\title{
Centralidades urbanas e oferta de transporte público coletivo em Goiânia-GO, 2014
}

\author{
Wilson Lopes Mendonça Neto ${ }^{1}$ e Érika Cristine Kneib²
}

\begin{abstract}
Resumo: O objetivo desse trabalho consiste na identificação de centralidades urbanas e posterior análise da oferta de transporte público coletivo (TPC) nessas áreas, em Goiânia. Para a identificação de centralidades utilizou-se a Análise Exploratória de Dados Espaciais, análises estatísticas e investigações sobre outliers. A operacionalização dos procedimentos foi realizada por meio da utilização de ferramentas de Sistemas de Informações Geográficas que tiveram como foco quatro variáveis: média de renda, densidade populacional, densidade de linhas e densidade de oferta de transporte coletivo. Foram gerados gráficos, resumos estatísticos, BoxPlots e mapas temáticos agregados em infográficos. A análise espacial foi realizada por meio da geração de mapas de espalhamento de Moran (BoxMap). Os resultados permitiram identificar centralidades com alta e baixa oferta de TPC e, também, concluir que existe grande descompasso entre políticas de mobilidade com políticas de expansão urbana no caso analisado.
\end{abstract}

Palavras-chave: centralidades urbanas; transporte coletivo; análise exploratória de dados espaciais; Goiânia.

\begin{abstract}
The aim of this study is the identification of urban centralities and analysis of public transportation supply in these areas, in Goiania. To identify centralities were used some tools, as the Exploratory Analysis of Spatial Variables, statistical analyzes and investigations of outliers. The operationalization of the procedures was performed through the use of Geographic Information Systems focused on four variables: average income, population density, density of public transportation lines and density of public transportation supply. Infographics gathering graphs, statistical summaries and boxplots and thematic maps were generated. Spatial analysis was performed by generating maps of scattering Moran (BoxMap). The results showed centralities with high and low supply of public transportation and, also, allowed to conclude that there is a large gap between mobility policies with policies of urban expansion, on the studied case.
\end{abstract}

Keywords: urban centrality; public transportation; exploratory spatial data analysis; Goiânia.

\section{INTRODUÇÃO}

As cidades estão enfrentando problemas cada vez mais desafiadores relacionados à mobilidade das pessoas como, por exemplo, congestionamentos, aumento da poluição e degradação ambiental, dentre outros aspectos. Questões relacionadas à mobilidade afetam diretamente a qualidade de vida, principalmente em grandes centros urbanos e acabam criando dificuldades crescentes de deslocamentos. Este cenário é observado em Goiânia, capital do Estado de Goiás, objeto do presente estudo, cuja divisão modal revela a priorização do deslocamento motorizado individual.

A rápida expansão urbana observada em Goiânia resulta na constituição de espaços diferenciados em vários sentidos, seja considerando questões de ordem econômica e de segregação socioespacial, seja pelos adensamentos populacionais ou, ainda, a disponibilidade de infraestrutura como vias de circulação e outros equipamentos urbanos. Nesse cenário, o uso dos espaços públicos é permeado de conflitos existentes entre as pessoas de diferentes níveis de renda e, também, pelo uso das vias por meio dos diferentes modos de transporte (PASQUALETTO, 2013).

\footnotetext{
Wilson Lopes Mendonça Neto, Instituto de Estudos Socioambientais - IESA, Departamento de Geografia da Universidade Federal de Goiás UFG (wilsonlopesmneto@gmail.com).
}

Érika Cristine Kneib, Faculdade de Artes Visuais - FAV, Programa de Pós Graduação Projeto e Cidade, Universidade Federal de Goiás - UFG (erikakneib@ufg.br).

Manuscrito recebido em 03/05/2015 e aprovado para publicação em 22/12/2015

Este artigo é parte de TRANSPORTES v. 24, n. 1, 2016 ISSN: 2237-1346 (online). DOI:10.14295/transportes.v24i1.916
O Ministério das Cidades (2007) define a mobilidade como expressão dos deslocamentos de pessoas e cargas que ocorrem por diversos meios de transporte (modos) e diversos motivos. Se a mobilidade é uma expressão dos deslocamentos de pessoas e/ou cargas, a fim de se planejar ações ou políticas de mobilidade urbana, é primordial a identificação, a localização e o diagnóstico da estrutura socioespacial urbana. Nesse sentido é possível questionar: onde estão as concentrações populacionais em Goiânia? Quais são os polos geradores de viagens? E, ainda, quais são os níveis de oferta de transporte coletivo disponíveis para população em diferentes localidades de Goiânia?

Com o intuito de responder essas questões e, assumindo o objetivo de identificar centralidades urbanas e analisar a oferta de TPC nessas áreas, assume-se nesse trabalho que as áreas centrais de Goiânia correspondem a polos geradores de viagens. O Ministério das Cidades (2007) define áreas centrais como lugares de concentração de atividades econômicas incluindo, além dos centros tradicionais das cidades, os polos regionais secundários e as novas centralidades que a dinâmica da expansão urbana geral.

É preciso ressaltar, contudo, que reside nesse objetivo o desafio de definir quais procedimentos são os mais adequados para realização da dupla missão de identificar as centralidades urbanas de Goiânia e, também, correlacionar essas centralidades com a oferta de TPC. Mediante esse desafio, optou-se pela aplicação de técnicas destinadas a realização de Análise Exploratória de Dados Espaciais - AEDE e, também, de procedimentos voltados a investigação de outliers. Essa opção foi realizada com base no potencial analítico que aplicações de técnicas de AEDE oferecem por meio de resultados que valorizam a dimensão empírica dos fenômenos investigados. Assim, entende-se que produtos resultantes da aplicação de técnicas 
de AEDE como tabelas, gráficos, mapas e diagramas, entre outros de base estatística, favorecem análises quantitativas, descritivas e espaciais das variáveis. Ressalta-se que as técnicas de AEDE foram aplicadas por meio da utilização de ferramentas de Sistemas de Informações Geográficas - SIG e utilização de planilhas de cálculo e, nesse sentido, foram desenvolvidas análises para quatro variáveis: densidade populacional, média de renda, densidade de linhas de ônibus e densidade de oferta de transporte coletivo.

A AEDE consiste em um conjunto de técnicas voltadas para descrição da distribuição dos dados espaciais, identificando localizações atípicas (outliers), ou procurando descobrir padrões de associação espacial (clusters). Para Druck et al. (2004), a análise exploratória de dados espaciais é realizada geralmente por meio de mapas e gráficos e deve permitir descrever a distribuição dos valores das variáveis em estudo. A escolha das variáveis se deu pela importância atribuída as mesmas por autores como McDonald e Prather (1994), Ojima (2007) e Kneib (2008 e Kneib e Silva, 2014) ao realizarem estudos sobre centralidades e identificação hierárquica de subcentros e, também, pela disponibilidade de dados para Goiânia.

Por meio da análise dos resultados foi possível identificar diferenças de concentrações populacionais no espaço urbano de Goiânia, padrões espaciais para diferentes classes de renda, diferenças na distribuição de serviços de mobilidade (densidade de linhas de TPC) e distintos níveis de acessibilidade (densidade de oferta de TPC). Os resultados permitiram a identificação de áreas centrais com baixa oferta de TPC, o que reflete, na prática, em problemas cotidianos relacionados à dificuldade de deslocamento dos cidadãos em Goiânia e, também, em desafios para o planejamento e gestão de políticas e ações voltadas à mobilidade urbana.

\section{REFERENCIAL, MATERIAIS E MÉTODOS}

$\mathrm{O}$ arcabouço teórico precípuo do presente trabalho baseia-se em três temas: centralidades; mobilidade e transporte público coletivo; e análise espacial. Com relação às centralidades, adota-se o conceito desenvolvido por Kneib (2008 e Kneib e Silva, 2014), no qual os subcentros constituem-se em áreas com significativa geração de viagens, complementado pelos conceitos de Rodrigue (2006), segundo o qual as centralidades funcionam como pontos nodais de uma rede espacial urbana.

O Ministério das Cidades (2007) define a mobilidade como expressão dos deslocamentos de pessoas e cargas que ocorrem por diversos modos de transporte e diversos motivos. Também relaciona mobilidade com acessibilidade na medida em que existem diferenças nas possibilidades de acessar as infraestruturas urbanas destinadas a deslocamentos de pessoas e cargas, tais como o sistema viário ou as redes de transporte público coletivo - TPC, o que define condições maiores ou menores de mobilidade para os indivíduos isoladamente ou, ainda, para partes inteiras do território.

Sobre o modelo espacial adotado em Goiânia, Kneib (2012) ressalta que somente no último Plano Diretor (Prefeitura Municipal de Goiânia, 2007) é que se verificam abordagens sobre pedestres, ciclovias e acessibilidade, no âmbito da mobilidade urbana. Este Plano Diretor aposta em um modelo espacial preconizado pelo Novo Urbanis- mo, que se baseia na estratégia da cidade compacta, com foco no adensamento em corredores estruturantes da cidade, dotados de infraestrutura adequada para prover grande oferta de transporte coletivo, com prioridade para os ônibus. Porém, segundo a autora, apesar de ser repleto de boas intenções, pouco do planejado foi aplicado desde então para garantir a eficiência do serviço de transporte público. Tais fatos corroboram a importância das análises pretendidas por este trabalho, inclusive para contribuir com a análise do modelo espacial de Goiânia.

As análises espaciais de Goiânia foram fundamentadas em informações da Pesquisa Nacional por Amostra de Domicílios - PNAD realizada pelo Instituto Brasileiro de Geografia e Estatística - IBGE no ano de 2011 e, também, dados disponibilizados pela Rede Metropolitana de Transportes Coletivos - RMTC com informações (em formato shapefile e tabelas . $x l s x$ ) sobre o número e a frequência das linhas, pontos e terminais de ônibus em Goiânia, para o ano de 2014 (RMTC, 2014).

Como suporte para elaboração dos produtos cartográficos apresentados, foram utilizados arquivos vetoriais no formato shapefile disponibilizados pela Companhia de Processamento de Dados do Município de Goiânia - COMDATA na forma de banco de dados espaciais, denominado de Mapa Urbano Básico Digital de Goiânia - MUBDG.

Para fins de planejamento e execução da PNAD o IBGE definiu a divisão do município de Goiânia em 1.636 setores censitários dos quais 12 são classificados como rurais e 1.624 como urbanos. O setor censitário é a menor unidade territorial, formada por área contínua, contida em área urbana ou rural com dimensões adequadas à operação de pesquisas cujas amostragens tendem a abarcar a totalidade do Território Nacional (IBGE, 2011). Pensar em nível de setor censitário em Goiânia, cidade central de sua região metropolitana, implica considerar unidades espaciais menores que o bairro. Dessa forma, um bairro pode conter diversos setores censitários.

Foram utilizadas as variáveis de média de renda e densidade populacional da PNAD (2011) e, também, densidade de linhas de ônibus e densidade de oferta de transporte coletivo, elaboradas a partir de dados disponibilizados pela RMTC (2014).

Os valores da média de renda correspondem aos valores médios da renda domiciliar das pessoas responsáveis pelo domicílio em um dado setor censitário. A densidade populacional foi calculada dividindo-se o número total de moradores de um dado setor censitário por sua área. A densidade de linhas foi calculada dividindo-se o número de linhas de ônibus que passam por determinado setor censitário por sua área. A densidade de oferta de transporte coletivo (ônibus) foi calculada somando-se a frequência diária de cada linha de ônibus que passa por determinado setor censitário e dividindo o resultado pela área do setor. A frequência corresponde ao número de viagens realizadas em cada linha do transporte coletivo em dias úteis.

O tratamento inicial das variáveis consistiu na elaboração de planilhas de cálculo a partir das quais foram organizados BoxPlots, uma tabela com resumo estatístico dos valores das variáveis e um gráfico com as porcentagens de clusters e outliers para cada variável analisada. As tabelas foram vinculadas a base cartográfica por meio do software 
ArcGis v.10.0 que foi utilizado para o desenvolvimento e geração de mapas temáticos. Os BoxPlots, os resumos estatísticos, o gráfico e os mapas foram reunidos em infográficos para cada uma das variáveis.

Em seguida as variáveis foram normalizadas de tal forma que a soma de seus valores correspondesse a 1. Não havendo valores negativos, todos os valores ficaram entre $0-1$. Foi calculada a média simples da soma dos valores de cada variável por setor censitário que também foi normalizado.

A média normalizada foi considerada como uma expressão da relação de centralidade entre áreas. Valores mais altos indicam concentração de renda, de população, de linhas de ônibus e de oferta de transporte coletivo, sendo interpretados como possíveis áreas centrais. Valores mais baixos indicam baixa concentração de renda, de população, de linhas de ônibus e de oferta de transporte coletivo, sendo interpretados como possíveis áreas periféricas.

A tabela foi vinculada ao arquivo shapefile com os polígonos dos setores censitários. O programa TerraView v.4.2.2 foi utilizado como subsídio a realização da análise espacial da média normalizada por meio do cálculo do Diagrama de Espalhamento de Moran (DRUCK et al. 2004) que foi analisado e apresentado na forma de um BoxMap.

O BoxPlot é um gráfico construído a partir de medidas da distribuição do conjunto de valores de uma dada variável. As cinco medidas utilizadas na composição do gráfico são importantes para analisar a posição, dispersão e assimetria da distribuição dos dados. São elas: valor mínimo, primeiro quartil (Q1), mediana (segundo quartil Q2), terceiro quartil (Q3) e valor máximo.
O gráfico é formado por uma caixa construída paralelamente a escala dos dados e representa os valores centrais da amostra (50\% dos valores de toda a amostra). O primeiro quartil corresponde ao percentil 25 e o terceiro quartil corresponde ao percentil 75. O valor mínimo corresponde ao menor valor da amostra que esteja entre Q1 e $\left\{\mathrm{Q} 1-1,5^{*} \mathrm{AIQ}\right\}$, sendo AIQ a distância interquartil obtida pela diferença entre Q3 e Q1 (Q3-Q1). O valor máximo corresponde ao maior valor da amostra que esteja entre Q3 e $\left\{\mathrm{Q} 3+1,5^{*} \mathrm{AIQ}\right\}$. Os valores das variáveis maiores que o valor máximo (expressos nos BoxPlots pela letra $\mathrm{x}$ ) e menores que o valor mínimo (para as variáveis analisadas não foram identificados outliers menores que o valor mínimo) são consideradas outliers, ou seja, valores que não obedecem ao padrão do conjunto de dados ao qual eles pertencem, sendo encarados como valores extremos (NEPOMUCENA; CIRILLO, 2001).

Para Soares et al. (2004) determinar valores outliers é subjetivo. A definição de outliers é sujeita a análise e interpretação de resultados e decisões sobre a identificação devem ser dependentes dos experimentos dos quais emanam. $\mathrm{O}$ tratamento dado a valores outliers e sua interpretação também é subjetivo. No presente trabalho optou-se por não desconsidera-los, ao contrário, optou-se por espacializá-los para melhor analisá-los. Seria possível identificar fenômenos socioespaciais por meio da análise dos outliers das variáveis definidas? Tendo como preocupação a dimensão espacial das variáveis, o que significam os valores outliers?

O Diagrama de Espalhamento de Moran corresponde a uma forma de visualizar a dependência espacial. A ideia

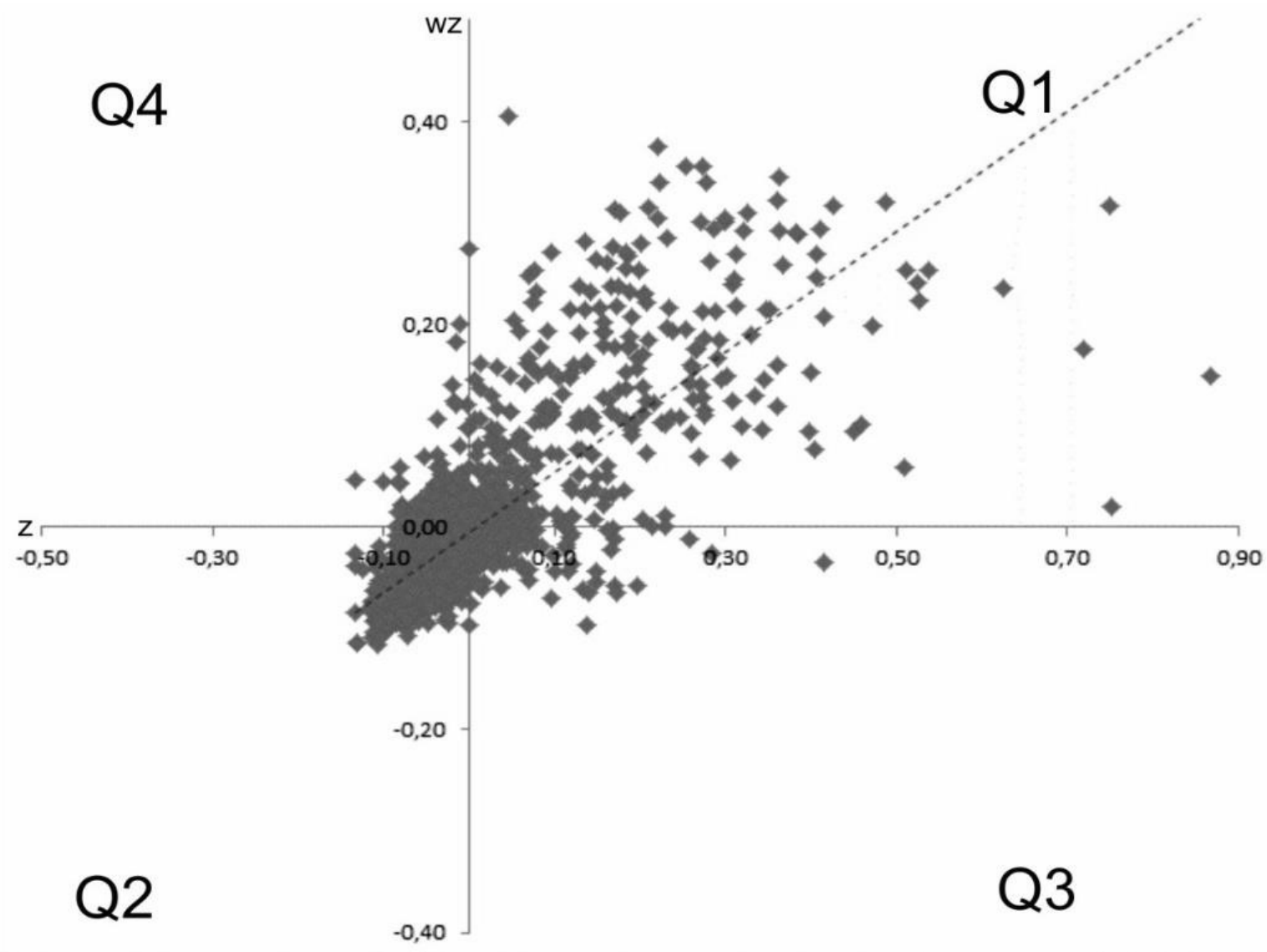

Figura 1: Diagrama de Espalhamento de Moran para a Média Normalizada da soma dos valores das variáveis.

Nota: Dados trabalhados pelos autores. 
fundamental do diagrama é comparar valores de um dado atributo de uma área com os valores de seus vizinhos. Seu desenvolvimento resulta na geração de um gráfico bidimensional de z (valores normalizados) e wz (média dos vizinhos). O gráfico é dividido em quatro quadrantes; Q1 representa valores positivos e associados a médias positivas, Q2 representa valores negativos associados a médias negativas. Esses dois quadrantes indicam associação espacial positiva levando em conta que numa localização há vizinhos com valores semelhantes. Q3 representa valores positivos associados a médias negativas e Q4 representa valores negativos associados a médias positivas que indicam associação espacial negativa considerando que numa localização há vizinhos com valores distintos (fig. 1).

Dessa forma, no diagrama de espalhamento de Moran os setores censitários localizados nos quadrantes Q1 e Q2 indicam associação espacial positiva, que corresponde à dependência espacial dos valores assumidos. A noção de dependência espacial parte de Waldo Tobler (1970) apud Druck et al. (2004) que enuncia "todas as coisas são parecidas, mas coisas mais próximas se parecem mais que coisas mais distantes". Para Druck et al. (2004) a maior parte das ocorrências naturais ou sociais apresenta entre si uma relação que depende da distância. Os setores censitários localizados nos quadrantes Q3 e Q4 podem ser interpretados como localidades que não seguem os mesmos padrões espaciais de seus vizinhos.

Cada setor censitário foi, então, vinculado a um quadrante que indica uma relação de associação espacial positiva ou negativa. Esse vínculo foi expresso em um mapa de espalhamento de Moran (BoxMap) no qual cada setor censitário foi representado por uma cor relacionada ao quadrante ocupado. Os setores censitários que apresentaram os maiores valores da média normalizada calculada foram considerados como áreas com fortes relações de centralidade.

Após a identificação das centralidades urbanas, o próximo passo consistiu em identificar as áreas de alta e baixa oferta de TPC, o que foi feito por meio da geração de um BoxMap para variável densidade de oferta de transporte público coletivo. Dessa forma, os valores da referida variável foram vinculadas a um dos quadrantes do diagrama de espalhamento de Moran. Os valores alocados nos quadrantes 1 e 3 foram considerados como alta oferta de TPC e, os valores alocados nos quadrantes 2 e 4 foram considerados como baixa oferta de TPC. A alta e a baixa oferta foram, então, sobrepostas ao shapefile de centralidades o que permitiu a identificação de menores ofertas de TPC em áreas centrais.

\section{RESULTADOS}

Os infográficos resultantes das análises de cada uma das variáveis são apresentados a seguir. A Figura 2 apresenta o infográfico da variável densidade populacional. São perceptíveis os adensamentos no entorno dos núcleos pioneiros orientados a partir da região centro-sul, entre o St. Central e Aparecida de Goiânia, e no sentido noroeste na direção de Trindade e Goianira. 8\% dos setores censitários foram identificados como outliers. Destaca-se a região do St. Bela Vista e a parte sul do St. Bueno enquanto áreas

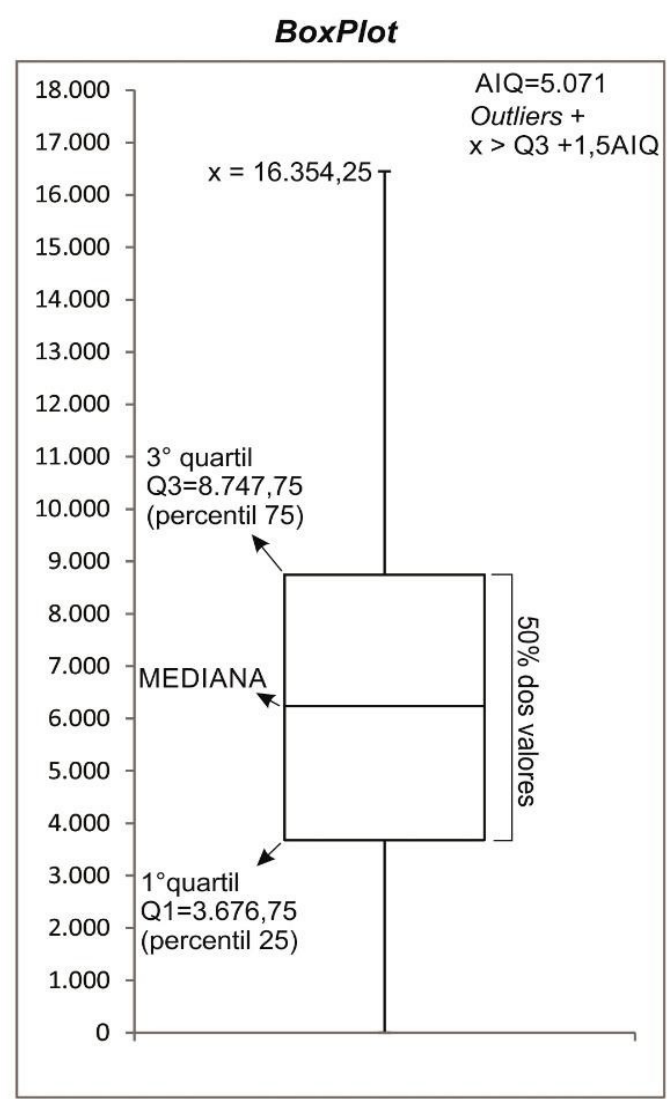

\begin{tabular}{|l|r|}
\multicolumn{2}{c}{ Estatística descritiva } \\
\hline Média & 7654,809291 \\
\hline Mediana & 6234 \\
\hline Modo & 0 \\
\hline Desvio padrão & 7491,900823 \\
\hline Mínimo & 0 \\
\hline Máximo & 71373 \\
\hline Contagem & 1636 \\
\hline
\end{tabular}
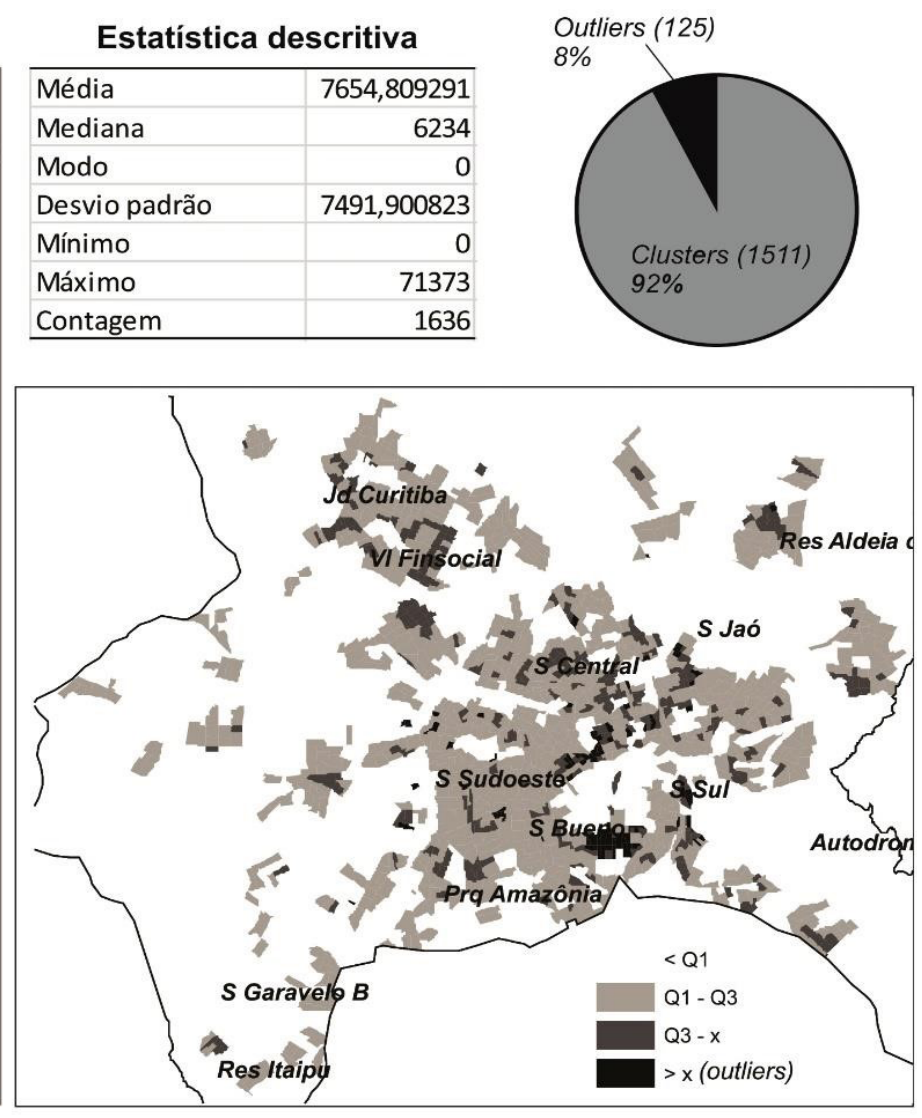

Figura 2: Infográfico da variável densidade populacional.

Nota: Dados trabalhados pelos autores. 


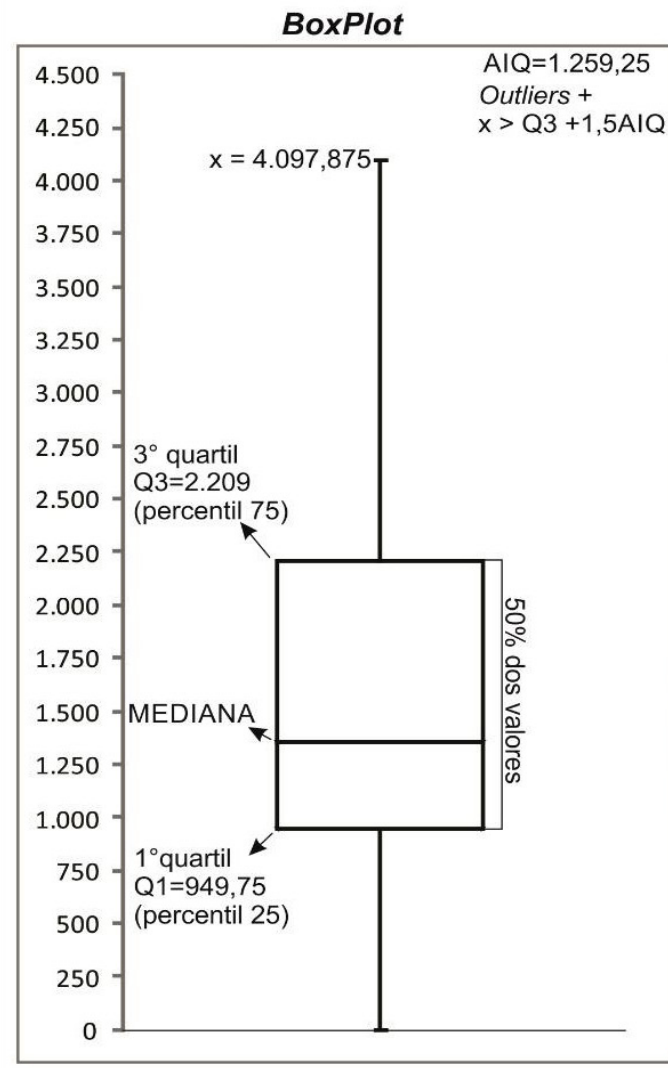

\begin{tabular}{|l|r|}
\multicolumn{2}{c}{ Estatística descritiva } \\
\hline Média & 1996,659 \\
\hline Mediana & 1350,5 \\
\hline Modo & 0 \\
\hline Desvio padrão & 1832,44 \\
\hline Mínimo & 0 \\
\hline Máximo & 18131 \\
\hline Contagem & 1636 \\
\hline
\end{tabular}
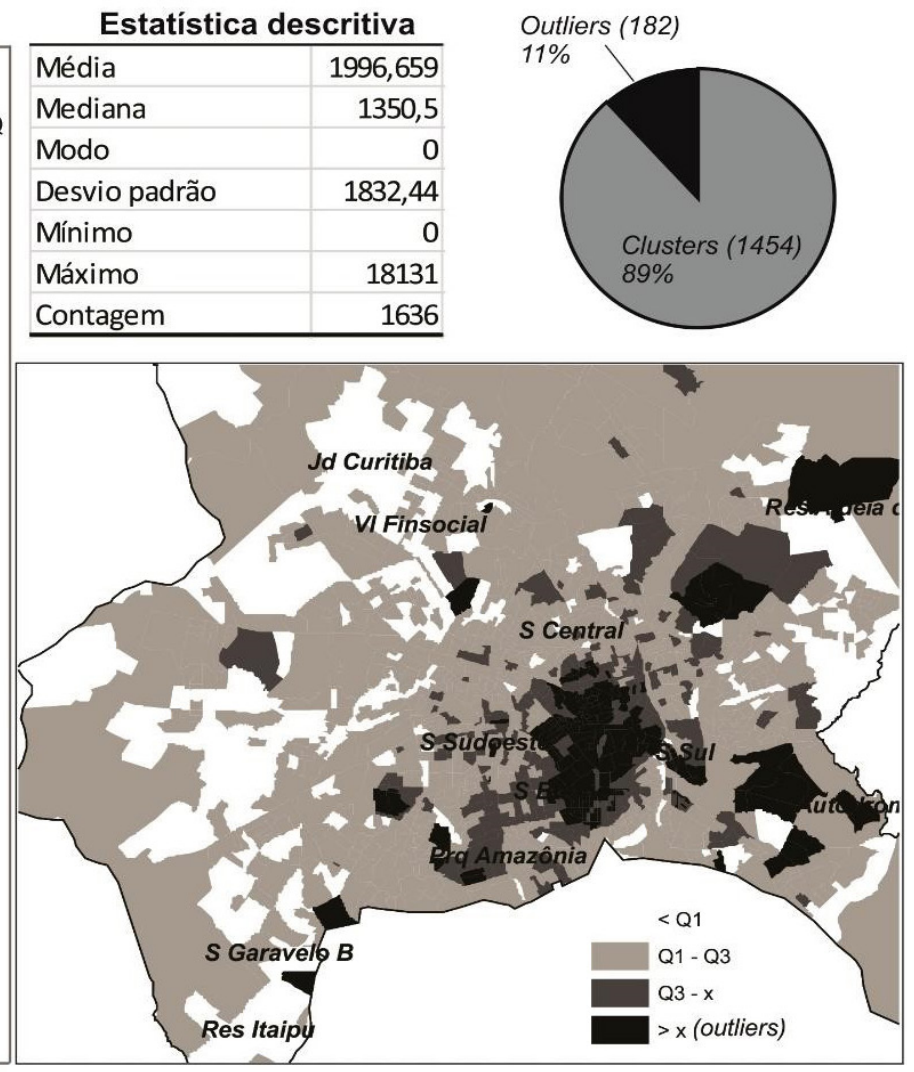

Figura 3: Infográfico da variável média de renda.

com as maiores densidades populacionais que ultrapassam $16.000 \mathrm{hab} . / \mathrm{km}^{2}$. Esses números representam quase o dobro da média do conjunto de dados que fica em torno de 7.650 hab. $/ \mathrm{km}^{2}$. O desvio padrão calculado em 7.491,90 indica alto nível de dispersão dos valores em relação à média.

A Figura 3 apresenta o infográfico da variável média de renda. Essa variável apresentou um nítido padrão espacial. Os valores menores que Q1, estão dispostos nas regiões periféricas, principalmente no extremo oeste e no extremo leste. Há uma grande concentração de renda na região entre o St. Central, o St. Sul, o St. Bueno e o S. Sudoeste e no entorno do St. Jaó, com valores superiores a Q3. Os outliers representam $11 \%$ dos setores censitários nos quais a concentração de renda é extrema com valores superiores a R\$ 4.097,00 e localizados em regiões nobres próximas ao centro tradicional ou, em regiões periféricas. Nesse último caso é preciso ressaltar essas regiões periféricas que apresentam alta concentração de renda nada tem a ver com as periferias proletárias, são regiões que demonstram uma nova dinâmica iniciada principalmente na década de 1990 em Goiânia, caracterizada por loteamentos de alto padrão para construção de condomínios fechados de luxo, como o Aldeia do Vale e o Alphaville. Destaca-se também o St. Jaó pela alta concentração de renda.

A Figura 4 apresenta o infográfico da variável densidade de linhas de TPC. As regiões que apresentaram valores outliers de densidade de linhas de transporte público coletivo correspondem a $11 \%$ do total e estão concentradas entre o Setor Central de Goiânia até o Setor Bueno. Há alta concentração de linhas ao longo da Av. 85 e Mutirão na região do Setor Bueno, que fazem conexões no sentido norte-sul e, da Av. Anhanguera e Av. T-7 passando pelo Setor Oeste e Setor Sudoeste, fazendo conexões no sentido leste-oeste. A diferença entre média e mediana e o alto valor apresentado de desvio padrão apontam para a grande dispersão dos valores.

A Figura 5 apresenta o infográfico da variável densidade de oferta de TPC. Os valores de densidade de oferta de transporte coletivo apresentaram padrão espacial muito próximo da densidade de linhas. As diferenças ocorreram em virtude da frequência das linhas de ônibus computadas para o cálculo da oferta. Essas duas variáveis, interdependentes, são uma expressão direta da possibilidade dos citadinos de circular por meio do transporte público pelos espaços urbanos de Goiânia se vinculando com questões de acessibilidade e mobilidade, já que se deslocar envolve tempo e custos diferenciados para os diferentes sujeitos que habitam as diversas localidades que compõem o urbano goianiense. Essa variável apresentou os maiores valores de desvio padrão e, também, de número de outliers (13\%), o que significa que algumas regiões são muito mais acessíveis por transporte público coletivo do que outras.

As diferenças entre as variáveis densidade de oferta e densidade de linhas suscitaram uma questão interessante que perpassa pela diferença entre acesso e acessibilidade. Percebe-se, por exemplo, que a região próxima ao St. Garavelo apresenta um valor extremo de densidade de linhas, mas, não apresenta um valor extremo de densidade de oferta. Ora, possuir um número elevado de linhas significa ter acesso, contudo, isso pode não significar acessibilidade adequada, na medida em que há indícios de que não há frequência satisfatória dos ônibus que circulam por essas li- 


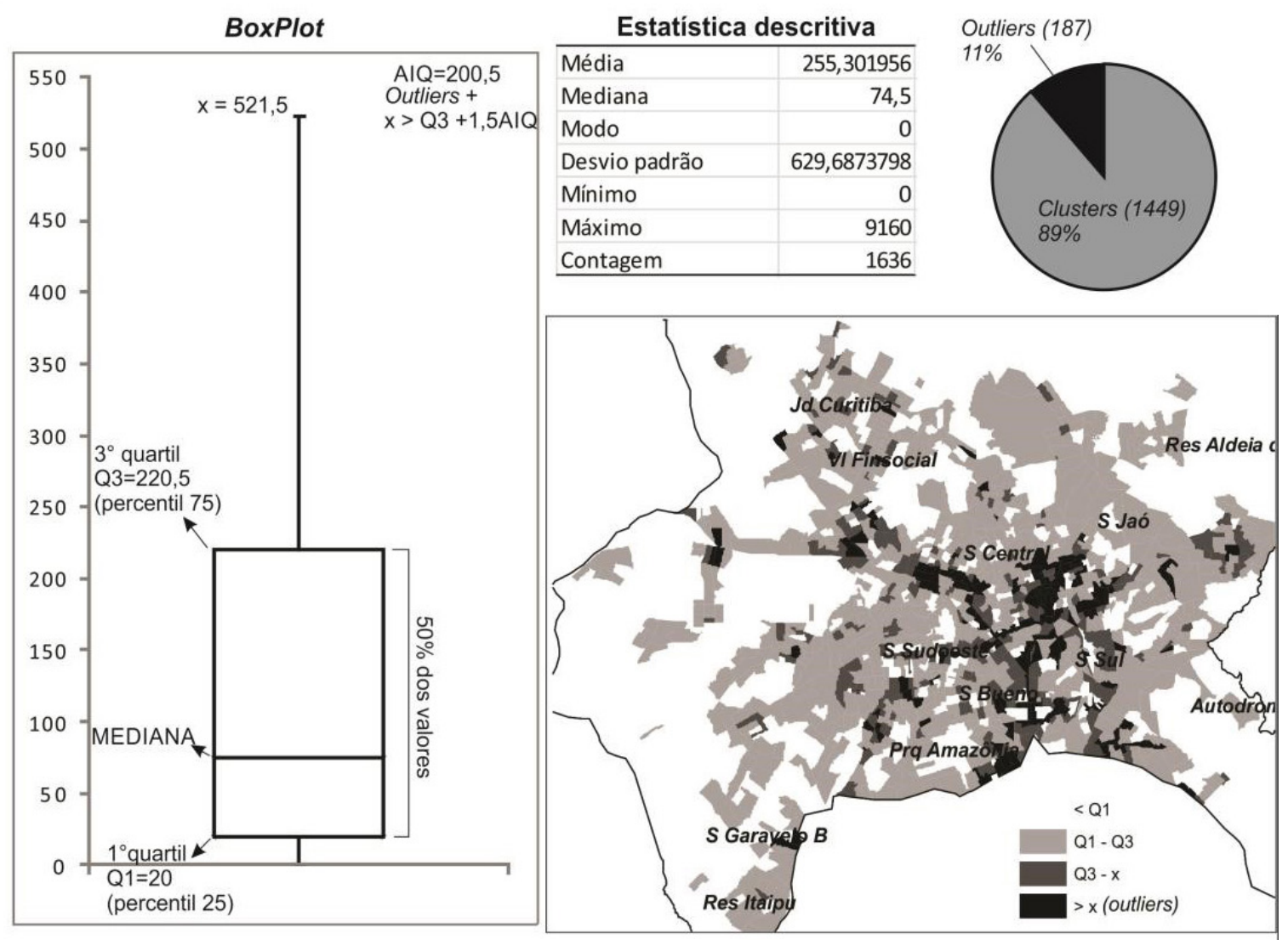

Figura 4: Infográfico da variável densidade de linhas de TPC.

Nota: Dados trabalhados pelos autores.

nhas. Esses indícios residem no fato da densidade de linhas nessa região possuir um alto valor e, ao mesmo tempo, a mesma região, apresenta uma densidade de oferta com um valor mais baixo.

Esse fato traduz a seguinte realidade: é possível acessar a infraestrutura de TPC que liga a diferentes pontos da cidade, contudo, a frequência dos ônibus parece não ser suficiente, o que implica em elevado tempo de espera nos pontos de parada. Dessa foram, pode-se afirmar que existe acesso ao sistema de TPC, porém, com acessibilidade reduzida. Todavia, para que se tenha um diagnóstico mais preciso sobre a falta de acessibilidade em localidades como o exemplo ressaltado, seria necessário um aprofundamento da análise relacionando mais precisamente demanda e oferta do transporte público em diferentes dias e horários, com foco, principalmente, para os horários de pico.

A Figura 6 apresenta o mapa que sintetiza as informações geradas a partir da sobreposição da alta e baixa oferta de TPC às áreas centrais. Dos 1.636 setores censitários considerados para análise, $462(28,28 \%)$ foram classificados como centralidades urbanas e $1.174(71,76 \%)$ foram considerados como áreas periféricas. Das centralidades urbanas, 172 foram identificadas com alta oferta de TPC e 290 foram consideradas com baixa oferta de TPC.

\section{CONSIDERAÇÕES FINAIS}

A análise dos resumos estatísticos e dos BoxPlots e a espacialização dos outliers foram procedimentos que subsidiaram a análise das variáveis permitindo a identificação de padrões de comportamento espacial. Nesse sen- tido, a análise conjunta das variáveis permitiu a identificação de áreas de adensamentos populacionais, diferenças e padrões espaciais da distribuição de renda, diferenças na distribuição do quantitativo de linhas de ônibus e diferenças nos níveis de acessibilidade.

A grande quantidade $(62,77 \%)$ de centralidades identificadas com baixa oferta de TPC indica áreas prioritárias para receberem estudos operacionais mais aprofundados sobre oferta e demanda, de modo a proporcionar melhorias ao usuário e mitigar possíveis dificuldades relacionados aos deslocamentos dos citadinos e, também, entraves referentes à mobilidade urbana de forma geral. Esse cenário pode refletir-se em custos mais altos ao serviço e aos usuários do TPC; e maior tempo gasto para realização dos deslocamentos.

Já as informações aqui produzidas, que revelam as áreas com grande oferta de TPC $(37,23 \%$ das centralidades), podem subsidiar políticas de adensamento, fomento às tais centralidades ou mesmo indicar áreas propícias à implantação de empreendimentos geradores de viagens, para melhor aproveitar a alta oferta de TPC já disponível nessas áreas.

A metodologia utilizada para identificação das centralidades - AEDE - demonstrou ser pertinente para a realização de uma análise ampla da estrutura socioespacial de Goiânia em escala de setor censitário. Contudo, conforme já ressaltado, os resultados obtidos carecem de maiores investigações que envolvam outros dados, principalmente, relacionados à demanda e oferta de TPC, com foco para horários de pico, envolvendo variáveis como principais pontos de origem e destino dos deslocamentos em diferentes 


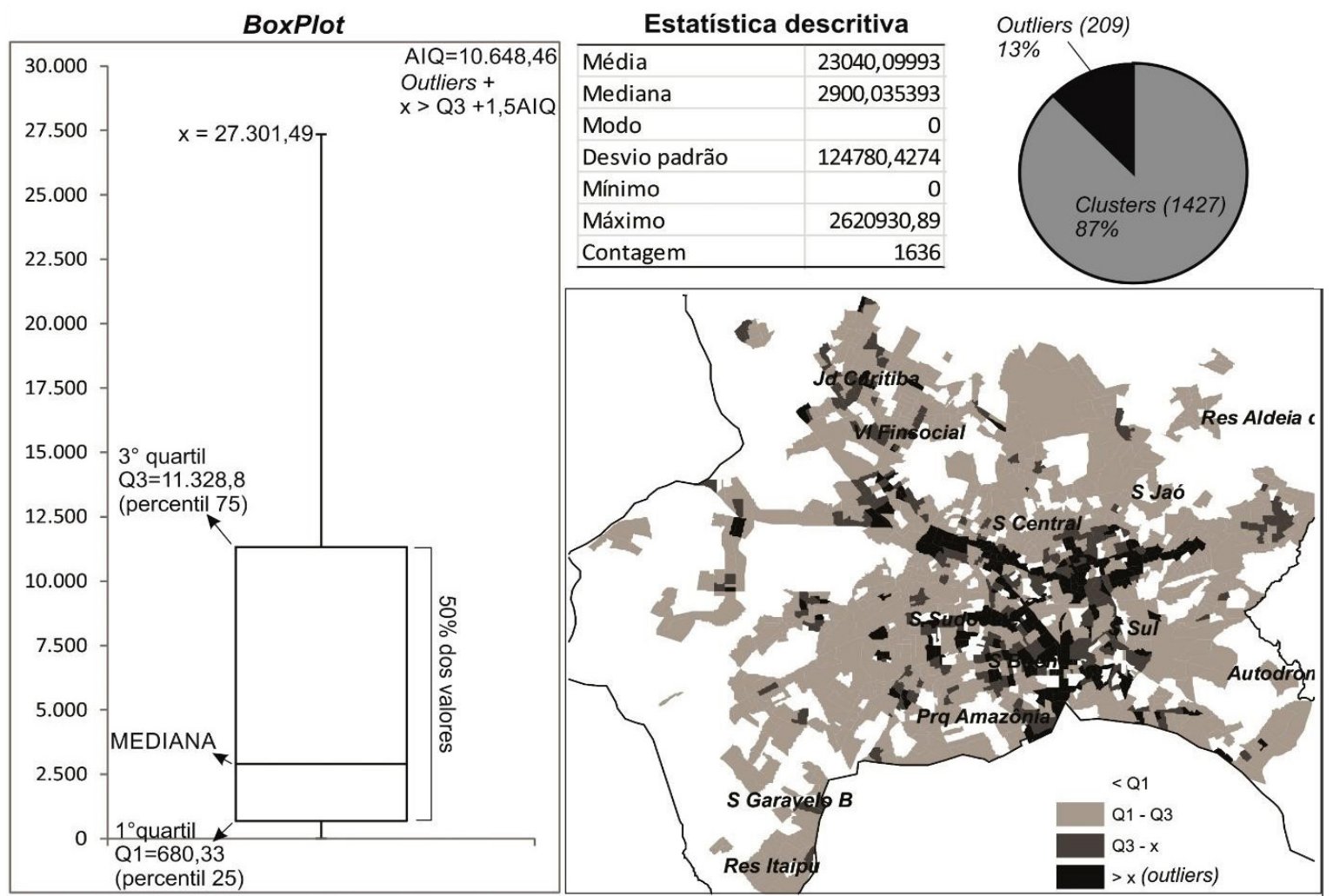

Figura 5: Infográfico da variável densidade de oferta de TPC.

Nota: Dados trabalhados pelos autores.

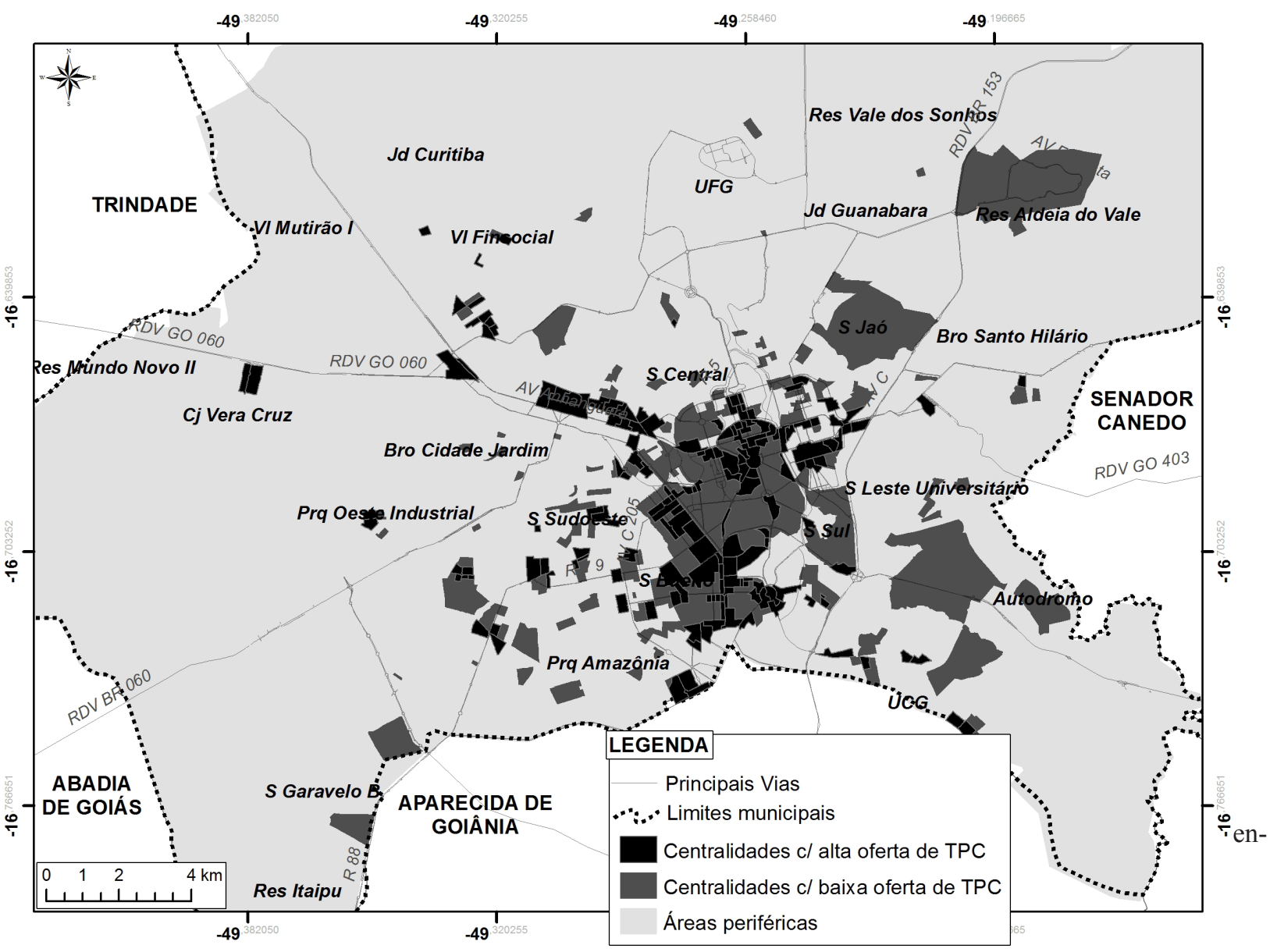

Figura 6: Mapa síntese das informações geradas a partir da sobreposição da alta e baixa oferta de TPC e centralidades.

Nota: Dados trabalhados pelos autores. 
regiões de Goiânia. Investigações mais aprofundadas sobre as centralidades, consideradas nesse trabalho como polos geradores de viagens, também seriam pertinentes e, nesse sentido, estudos sobre os principais motivos e modos de viagens constituiriam bons complementos para as análises apresentadas.

Os resultados obtidos corroboram com a ideia de Moysés et al (2007). Para os autores a construção de Goiânia está marcada por conflitos de interesse e a força do capital imobiliário, ao criar e recriar novas centralidades, empurra grandes levas da população para espaços distantes da malha urbanizada, longe do mercado de trabalho e com baixos níveis de acessibilidade aos equipamentos urbanos, o que compromete, inclusive, o atendimento da população por transporte coletivo e impacta diretamente a mobilidade urbana. Essa situação fica explícita quando se realiza a análise do desvio padrão para cada uma das variáveis. Os altos valores apresentados para essa medida de dispersão indicam que há forte diferença espacial na distribuição dos adensamentos populacionais, da renda, da densidade de linhas e, também, da densidade de oferta do TPC em Goiânia. Essa diferencialidade espacial resulta de uma cidade heterogênea, com infraestrutura urbana adensada em alguns pontos e espraiada em outros.

Os níveis mais baixos de acessibilidade foram identificados nas áreas periféricas, por meio da análise das variáveis densidade de linhas e densidade de oferta de transporte coletivo e são, também, as áreas com as menores médias de renda, o que revela um cenário de segregação socioespacial. Esse cenário, por certo, se constrói no contrassenso entre as políticas de planejamento urbano que tem priorizado áreas de alta densidade populacional, que deveriam ser acompanhadas de grande oferta de transporte público coletivo - por meio de corredores conhecidos como Bus Rapid Transit (BRT), ou corredores preferenciais, conhecidos como Bus Rapid Service (BRS), que deveriam perpassar, circundar e conectar áreas centrais - baseando-se num modelo de cidade compacta; e a força econômica e política do capital imobiliário que cria mecanismos de valorização de áreas próximas a centralidades, empurrando grandes levas da população para áreas mais longínquas nas quais, somente depois da ocupação, o transporte público precisa se adequar.

A divergência entre o modelo idealizado em Goiânia - de cidade compacta com grande oferta de transporte coletivo - e a realidade revelada no presente estudo revela fortes indícios que há uma grave ausência de integração entre políticas de mobilidade e transporte público com políticas de uso e ocupação do solo, merecendo este tema uma análise detalhada, a partir da continuação da presente pesquisa.

\section{REFERÊNCIAS}

Arrais, T. A. (2013). A produção do território goiano: economia, urbanização, metropolização. Goiânia: Editora UFG.

Beaujeu-Garnier, J. (1997). Geografia urbana. Lisboa: Fundação Calouste Gulbenkian.

Bicca, B. E. P; Bicca, P. R. S. (2008). Arquitetura na formação do Brasil. Brasília: UNESCO, IPHAN.
Brasil. (2012) Lei $n^{\circ} 12.587$, de 3 de janeiro de 2012. Institui as diretrizes da Política Nacional de Mobilidade Urbana e dá outras providências.

Druck, S; Carvalho. M. S; Câmara, G; Monteiro, A. V. M. (2004). Análise espacial de dados geográficos. Brasília, EMBRAPA.

Gottdiener, M. (1993). A produção social do espaço urbano. São Paulo: Editora da Universidade de São Paulo.

IBGE. PNAD (2011). Síntese de Indicadores 2011. Disponível em: < http://www.ibge.gov.br/home/estatistica/populacao/trabalhoerendimento/pnad2011/default_sintese.shtm >. Acesso em: 10 ago. 2013.

Kneib, E. C. (2008). Subcentros urbanos: contribuição conceitual e metodológica à sua definição e identificação para planejamento de transportes. Tese (Doutorado) - Universidade de Brasília. Distrito Federal.

Kneib, E. C. (2012). Mobilidade urbana e qualidade de vida: do panorama geral ao caso de Goiânia. Revista UFG, v.13, n. 12.

Kneib, E. C.; Silva, P. C. M. da (2014). Identificação de subcentros urbanos para planejamento de transportes e mobilidade: contribuição conceitual e metodológica a partir da estatística espacial. In: Kneib, E.C. (org.). Projeto e cidade: centralidades e mobilidade urbana. Goiânia, FUNAPE.

Lefebvre, H. (1999). A revolução urbana. Belo Horizonte: Ed. UFMG.

Mcdonald, J. F; Prather, P. J. (1994). Suburban employment centers: the case of Chicago. Urban Studies, 31, p. 201-218.

Ministério das Cidades. (2007). Caderno de referência para elaboração de plano de mobilidade urbana. Brasília.

Moysés, A; Silva, E. R.; Borges, E. M; Ribeiro, M. G. (2007). Da formação urbana ao empreendedorismo imobiliário: a nova face da metrópole goianiense. Mercator: Revista de Geografia da $U F C$, v. 6, n. 12.

Nepomucena, T. M; Cirillo, M. Â. (2001). Observação de outliers por alocação das observações através do modelo de Poisson aplicado ao número de casos de AIDS diagnosticados no Brasil. Semina: Ciências Biológicas da Saúde, Londrina, v. 31, n.1.

Ojima, R. (2007). Dimensões da urbanização dispersa e proposta metodológica para estudos comparativos: uma abordagem socioespacial em aglomerações urbanas brasileiras. Revista Brasileira de Estudos Populacionais. São Paulo, v. 24, n. 2, p. 277-300, jul./dez.

Pasqualetto, A. (2013). Cálculo do índice de mobilidade urbana sustentável em Goiânia, monitoramento e auxílio nas políticas públicas. Anais: encontros nacionais da ANPUR, v. 15, p. 1-16. Disponível em: $<$ http://unuhospedagem.com.br/revista/rbeur/ index.php/anais/article/view/4159/4045>. Acesso em: 12 ago. 2013. 
Pastore, E. (1984) Renda fundiária e parcelamento do solo:

Goiânia (1933 - 1983). Dissertação (Mestrado) - Universidade de

Brasília.

Prefeitura Municipal de Goiânia (2007). Lei complementar $n^{\circ}$ 171, de 29 de maio de 2007- Dispõe sobre o Plano Diretor e o processo de planejamento urbano do Município de Goiânia e dá outras providências

Rodrigue, J. P. (2006). Transportation and urban form. In: . The Geography of transports sistems. Routledge.

Ribeiro, C. R. (2011). Avaliação da expansão urbana no município de Goiânia: período 1990 - 2010. Dissertação (Mestrado) - Pontifícia Universidade Católica de Goiás. Departamento de Ciências Econômicas.

Santos, M. (1981). Manual de geografia urbana. São Paulo: Hucitec.

Soares, A. S; Coelho, C. J; Laureano, G. T; Lucena, D. V; Galvão, R. K. H. (2004). Determinação de outliers para pequenas amostras. ENCONTRO REGIONAL EM MODELAGEM E ANÁLISE COMPUTACIONAL DE SISTEMAS, 1., 2004. Anais.... Goiânia, de 29 de setembro a $1^{\circ}$ de outubro.

Villaça, F. (2001) Espaço intra-urbano no Brasil. São Paulo: Studio Nobel: FAPESP; Lincoln Institute. 